\title{
Aggressive angiomyxoma of the vulva: an uncommon entity
}

\author{
Shradha Prajapati ${ }^{1 *}$, Meerabai V. ${ }^{1}$, Jayalakshmi M. ${ }^{1}$, Sredharan M. ${ }^{2}$
}

${ }^{1}$ Department of Obstetrics and Gynecology, ${ }^{2}$ Department of Surgery, Karpagam Faculty of Medical Science and Research, Othakkalmandapam, Coimbatore, Tamil Nadu, India

Received: 03 July 2017

Revised: 16 July 2017

Accepted: 29 July 2017

\section{*Correspondence:}

Dr. Shradha Prajapati,

E-mail: drshradhakanoriya@gmail.com

Copyright: (c) the author(s), publisher and licensee Medip Academy. This is an open-access article distributed under the terms of the Creative Commons Attribution Non-Commercial License, which permits unrestricted non-commercial use, distribution, and reproduction in any medium, provided the original work is properly cited.

\section{ABSTRACT}

AA is a rare locally invasive mesenchymal tumor predominantly presenting in women of reproductive age group, having a moderate to high risk for local relapse. Hence, it needs to be differentiated from another mesenchymal tumor occuring in this region. We present a case of a 50 year old female with a large, polypoidal, spongy mass on the right labia majora.

Keywords: Aggressive angiomyxoma, Labia majora, Mesenchymal tumor

\section{INTRODUCTION}

Aggressive angiomyxoma is a rare tumor with higher risk of infilteration and recurrence. The AA was first described by Steeper and Rosai in $1983 .{ }^{1}$ Tumor is aggressive due to its characteristically slow and insidious growth as well as carrying a moderate to high risk of local relapse. This tumor pathogenesis is unclear. ${ }^{2}$ It occur predominantly in vulvo-vaginal, perineal and groin region. Diagnosis is made by histology examination. ${ }^{3-6}$

Most of the cases reported have been in women at reproductive age and those in forth decade of life. The AA can affect the women and men in proportion of $6: 1$. Estrogen and progesterone receptor are commonly found in AA thus it is likely to grow during pregnancy and respond to hormonal manipulators. Considering its nature of aggression and chances of local relapse, appropriate management and long term follow up are necessary to diagnose early recurrence.

No single modality of treatment has been found to be proven benefit till now. However complete surgical excision- when possible should be sought. Where fertility is to be preserved or surgery is likely to be extensive and mutilating, incomplete resection is acceptable as local recurrences can be treated with further resection. ${ }^{7}$ Radiotherapy and chemotherapy have been used as adjunctive therapies but are unlikely to be useful as it has few mitotic activity. ${ }^{8-12}$ Despite of availability of many options of treatment, recurrence of AA is reported to be as high as $72 \%$.

\section{CASE REPORT}

A 50 Year old perimenopausal female (P2L2) presented with a slow growing mass on right labia majora since 6 month. She had history of similar right labial swelling 12 years back for which she underwent excisional surgery. Details are not available. There was no history of any vulval discharge, bleeding, sexual difficulty, or pain, except a sensation of weight hanging while standing. Local examination showed a well circumscribed polypoidal mass measuring $12 * 6 \mathrm{~cm}$. The mass was nontender, soft and spongy in consistency (Figure 1).

She is diabetic and on oral hypoglycemic drug. Blood investigations revealed uncontrolled sugar level. Ultrasonogrphy of local part showed a large heteroechoic lesion measuring $52 * 70 * 98 \mathrm{~mm}$ in right labia majora 
with internal vascularity. Few prominent ovoid lymph nodes with preserved fatty hilum seen in right inguinal region.

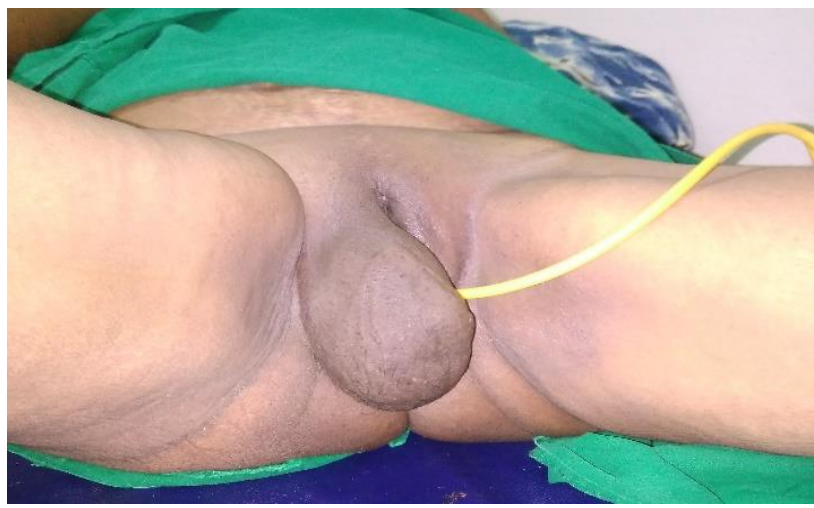

Figure 1: A well-defined polpoidal 12*6cm right labia majora swelling.

CT suggested multiloculated polypoidal complex cystic lesion in right labial region. With a clinical diagnosis of a vulvar fibroepithelial polyp or lipofibroma, she underwent for local excisional surgery (Figure 2).

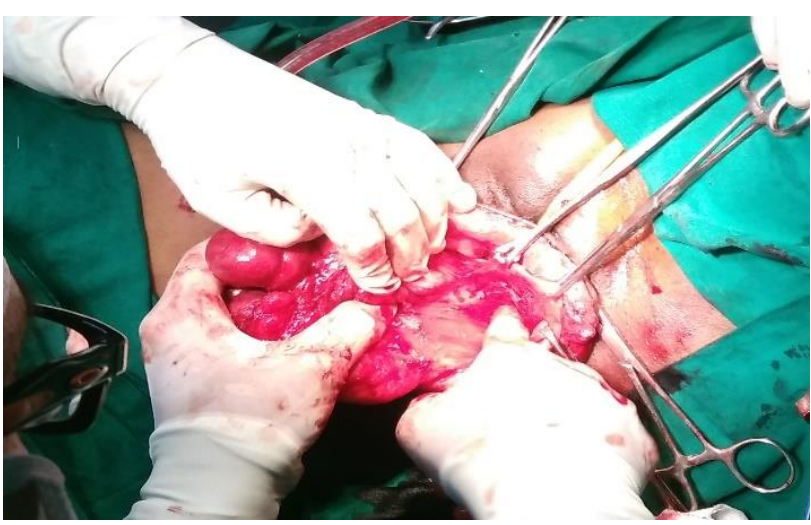

Figure 2: Local excisional surgery.

There was moderate bleeding during the procedure. The cut surface revealed a glistening, gelatinous, and soft homogeneous appearance (Figure 3).

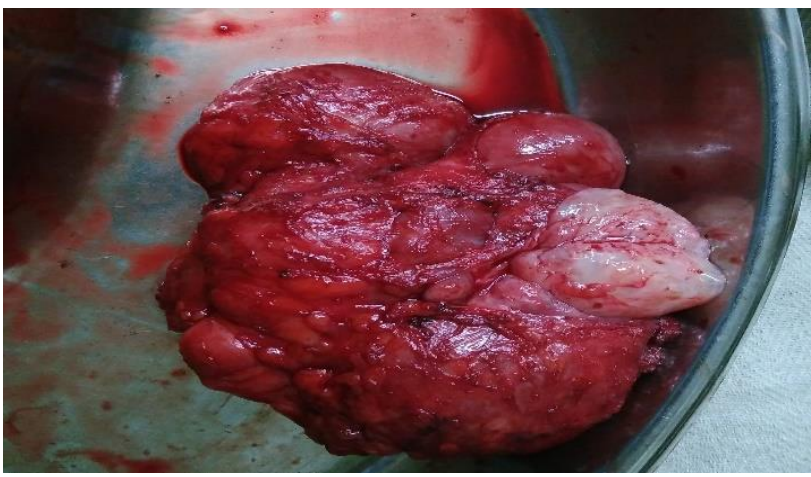

Figure 3: Specimen of angiomyxoma showing cut open homogenous white area.
On histopathology, Tumor composed of spindle fibroblast in hypocellular myxoid stroma. Many prominent dilated thick-walled blood vessels are seen. Admixed component of mature adipose is also noted. No nuclear atypia, hemorrhage or necrosis seen (Figure 4 a and $b$ ).

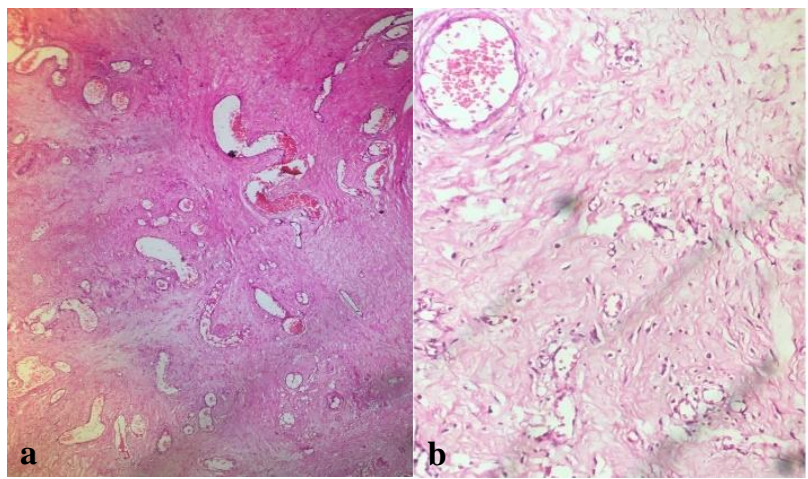

Figure 4: a-Angiomyxoma, b-High power picture of angiomyxoma ( $\mathrm{H}$ and $\mathrm{E})$.

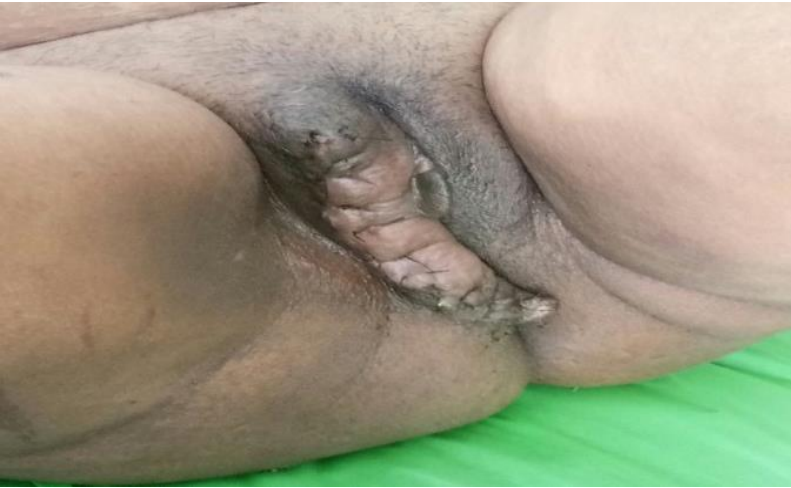

Figure 5: Post-operative picture.

\section{DISCUSSION}

The AA tumor commonly presents as an asymptomatic mass in the genital area of women in their reproductive life. The term aggressive denotes its propensity for local aggression and recurrence after excision. Clinically, AA may misdiagnosed as Bartholin cyst, lipoma, labial cyst, Gartner duct cyst, etc. Superficial angiomyxoma, angiomyofibroblastoma, cellular angiofibroma, and smooth muscle tumors also need to be considered in the differential diagnosis of a polypoidal mass in the perineum. AA is an infiltrative tumor whereas angiomyofibroblastoma is well circumscribed. In addition, AA has thick-walled vessels, which are less numerous than thin-walled vessels in angiomyofibroblastoma.

On CT scan, these tumors have a well-defined margin with attenuation less than that of muscle. The attenuation on $\mathrm{CT}$ and high signal intensity on magnetic resonance imaging (MRI) are likely to be due to the presence of loose myxoid matrix and high water content of AA. ${ }^{7}$ 
Usually, this tumor does not metastasize, but there are reports of multiple metastases in women treated initially by excision and ultimately succumbing to it. ${ }^{3,4}$

Partial excision may have to be done in view of high operative morbidity. ${ }^{9}$ Unfortunately, recurrence may still occur with negative margins. ${ }^{10}$ This may necessitate multimodal therapies using surgical and medical means to treat recurrent AA. ${ }^{11}$ There is no consensus regarding the pathogenesis of AA. This hormonally responsive tumor is believed to arise from specialized mesenchymal cells of the pelvic-perineal region or from the multipotent perivascular progenitor cells, which often display variable myofibroblastic and fibroblastic features. ${ }^{5}$ Immunohistochemically, most AA express different combinations of estrogen and progesterone receptors, vimentin, desmin, smooth muscle actin CD34, and CD44, but all are invariably negative for $\mathrm{S}-100$, carcinoembryonic antigen, and keratin..$^{9,11,12}$

Recent cytogenetic and molecular studies have revealed a variety of genetic alterations, involving the chromosome 12 , in the region $12 q 13-15$. A gene in this region, called high-mobility group protein isoform I-C (HMGI-C), which encodes proteins involved in the transcriptional regulation, appears to have a role in the pathogenesis of this tumor. Detection of inappropriate HMGI-C expression using the immunoperoxidase technique with anti-HMGI-C antibody may potentially be a useful marker for microscopic residual disease. ${ }^{6}$

Our patient had previous history of similar swelling 12 years before exact data not available but considering it as a relapse of AA we decided to start preventive therapy, i.e., GnRH agonist, etc.

Han-Geurts et al proposed the following guideline for treating AA:

- complete excision of the lesion when possible, avoiding mutilating surgery,

- $\quad$ adjunct therapy using arterial embolization and/or hormonal treatment needed in case of partial resection of the tumor, and

- radiotherapy is reserved for cases that are resistant to embolization and/or hormonal therapy and still symptomatic. $^{2}$

There are no specific guidelines for postoperative management of vulvar AA; however, due to high recurrence rate and potential morbidity associated with undiagnosed recurrences, several authors recommend a periodic evaluation with physical examination and MRI up to 15 years after excision. . $^{2,8}$

CT and MR imaging accurately reveal extension of these tumors across the pelvic diaphragm and are thus valuable in determining the surgical approach. ${ }^{13}$

\section{CONCLUSION}

This case report illustrates the challenges that a physician might face when dealing with a vulvar mass which may be an AA. Though it is a rare entity, it should always be considered, especially when it is an insidious painless lesion. High level of suspicion is needed to make a clinical diagnosis. All relevant hematological and radiological studies including MRI or CT scan should help in reducing the number of misdiagnosed cases of AA preoperatively. Once its anatomical location and extension, if any, are defined, any vulvar tumor particularly AA-can be optimally treated by surgical excision only, while avoiding any mutilating surgery. If complete resection is possible under the circumstances, one should expect lowest recurrence rate. AA is rarely life-threatening, and therefore one can afford to have a partial resection when high operative morbidity is anticipated. Irrespective of treatment modalities instituted postsurgery, it is evident that AA requires close and longterm follow-up.

\section{Funding: No funding sources \\ Conflict of interest: None declared \\ Ethical approval: Not required}

\section{REFERENCES}

1. Steeper TA, Rosai J. Aggressive angiomyxoma of the female pelvis and perineum. Report of nine cases of a distinctive type of gynecologic soft-tissue neoplasm. Am J Surg Pathol. 1983;7:463-75.

2. Han-Geurts IJ, van Geel AN, van Doorn L, M den Bakker, Eggermont AM, Verhoef C. Aggressive angiomyxoma: Multimodality treatments can avoid mutilating surgery. Eur J Surg Oncol. 2006;32:121721.

3. Siassi RM, Papadopoulos T, Matzel KE. Metastasizing aggressive angiomyxoma. N Engl J Med. 1999;341:1772.

4. Blandamura S, Cruz J, Faure Vergara L, Machado Puerto I, Ninfo V. Aggressive angiomyxoma: A second case of metastasis with patient's death. Hum Pathol. 2003;34:1072-4.

5. Alameda F, Munné A, Baró T, Iglesias M, Condom E, Lloreta-Trull $\mathbf{J}$ et al. Vulvar angiomyxoma, aggressive angiomyxoma, and angiomyofibroblastoma: An immunohistochemical and ultrastructural study. Ultrastruct Pathol. 2006;30:193-205.

6. Nucci MR, Fletcher CD. Vulvovaginal soft tissue tumours: Update and review. Histopathology. 2000;36:97-108.

7. Abu JI, Bamford WM, Malin G, Brown L, Davies Q, Ireland D. Aggressive angiomyxoma of the perineum. Int J Gynecol Cancer. 2005;15:1097-100.

8. Fine BA, Munoz AK, Litz CE, Gershenson DM. Primary medical management of recurrent aggressive angiomyxoma of the vulva with a gonadotropin- 
releasing hormone agonist. Gynecol Oncol. 2001;81:120-2.

9. Dierickx I, Deraedt K, Poppe W, Verguts J. Aggressive angiomyxoma of the vulva: A case report and review of literature. Arch Gynecol Obstet. 2008;277:483-7.

10. Chan YM, Hon E, Ngai SW, Ng TY, Wong LC. Aggressive angiomyxoma in females: Is radical resection the only option? Acta Obstet Gynecol Scand. 2000;79:216-20.

11. Dahiya K, Jain S, Duhan N, Nanda S, Kundu P. Aggressive angiomyxoma of vulva and vagina: A series of three cases and review of literature. Arch Gynecol Obstet. 2011;283:1145-8.
12. Sun NX, Li W. Aggressive angiomyxoma of the vulva: Case report and literature review. J Int Med Res. 2010;38:1547-52.

13. Outwater EK, Marchetto BE, Wagner BJ, Siegelman ES. Aggressive angiomyxoma: Findings on CT and MR imaging. AJR Am J Roentgenol. 1999;172:4358.

Cite this article as: Prajapati S, Meerabai V, Jayalakshmi M, Sredharan M. Aggressive angiomyxoma of the vulva: an uncommon entity. Int J Reprod Contracept Obstet Gynecol 2017;6:4154-7. 